\title{
Antecedentes de este Homenaje
}

Como complemento al testimonio de admiración y simpatía que en esta entrega especial de la Revista Iberoamericana rinde una veintena de los más distinguidos intelectuales de América al maestro Baldomero Sanín Cano, se reproducen a continuación algunos documentos publicados en el número dos, correspondiente a noviembre de 1939, de esta misma revista, reimpresos con fervorosa adhesión por Nosotros, de Buenos Aires, en la edición de enero-febrero de 1940. Hubiéramos deseado incluir igualmente algunas de las cartas enviadas por muchas de las figuras más destacadas del intelecto americano que en aquel año apoyaron la idea de un tributo internacional al gran escritor colombiano. La falta de espacio, por una parte, y, el hecho de que no pocos de los corresponsales de 1939 han contribuído con sendos trabajos en esta ocasión, y en ellos desarrollan los conceptos contenidos en las referidas epístolas, nos impiden darlas.

En cambio creemos pertinente señalar aquí los antecedentes de la pleitesía que por fin se le rinde hoy al decano de nuestros prosistas, si bien en forma mucho más mođesta de lo que él merece y nuestra cultura reclama. Como luego se verá, era algo más digno del homenajeado y de mayor provecho para nuestra cultura lo que en 1939 se pedia, pero... nuestra América no da para más.

Esta idea ha tenido una larga elaboración en la mente de algunos de nuestros escritores y la han apoyado varias de nuestras publicaciones periódicas más prestigiosas en los últimos once años. Si no andamos demasiado trascordados la hizo pública por primera vez un crítico antillano en la Revista Bimestre Cubana, en 1937. Huelga decir que la sugerencia no tuvo eco ninguno entre nuestros escritores ni fué acogida por ninguna entidad ni revista. Dos años más tarde, en 1939, el poco afortunado iniciador del proyecto presidía el Ins- 
tituto Internacional de Literatura Iberoamericana y aprovechó la circunstancia para renovar el empeño, reforzado esta vez con el apoyo unánime de la mesa directiva de la mencionada institución y el de la comisión redactora de la Revista Iberoamericana, de la cual era jefe entonces el doctor Carlos García-Prada.

Lo mismo en 1937 que en 1939, el plan de homenaje que se aconsejaba debía consistir en la recopilación de la obra escrita de don Baldomero Sanín Cano para publicarla en una serie de volúmenes y salvar así para la posteridad una de las más nobles y luminosas manifestaciones de alta cultura que en la vida literaria de nuestros países se ha producido en lo que va de siglo. (Esta ejemplar ejecutoria permanece todavía hoy diseminada en su mayor parte en gran número de publicaciones periódicas desparramadas por todo el continente.) A esta edición de las Obras completas de don Baldomero debían añadirse dos o tres volúmenes a él dedicados contentivos de trabajos de investigación literaria, filológica y gramatical o de ensayos críticos - ya filosóficos o literarios- que son las principales disciplinas cultivadas por el homenajeado. Tal se había hecho en España en honor de Menéndez Pelayo, Menéndez Pidal y Miguel Artigas y, en América, en los casos de Enrique José Varona y Domingo Amunátegui Solar.

Conscientes de la imposibilidad de encontrar editor para un plan de tan vastas proporciones, los promotores del proyecto en 1939 trataron de movilizar el interés cultural y de estimular el sentimiento patriótico de los hombres de letras que por aquellas calendas integraban el gobierno colombiano para que impartieran su aprobación al plan y la publicación pudiera hacerse por cuenta del gobierno.

Las circunstancias parecían propicias debido al hecho de que por aquellos días regían los destinos de la nación colombiana algunos de los más cảracterizados representantes de la vida cultural del país, tales como don Eduardo Santos que ocupaba la presidencia de la república, y en los ministerios Luis López de Mesa, Lozano y Lozano y otros. Esperanzados por lo que estimaban feliz coincidencia, los gestores del homenaje decidieron aprovechar la coyuntura confiados en que los elementos oficiales lo calorizarían y harían suyo ya que se trataba de honrar al valor más universal y de más fina calidad que Colombia ha producido y en él al país mismo. "Honrar honra", decía José Martí, y en la exaltación de su máximo ensayista y crítico, los gobernantes - creían los ingenuos proponentes de la 
idea- se sentirían orgullosos y honrados ellos mismos, máxime cuando el impulso venía desde fuera y lo respaldaban unas sesenta firmas de Europa y América de máxima solvencia intelectual.

A fin de persuadir a los señores gobernantes de Bogotá y demostrarles que el deseo de rendir tributo al patriarca de nuestras letras y maestro indiscutido e indiscutible de varias generaciones, no era un capricho de jóvenes exaltados y devotos ni cuestión de grupo o bandería, el presidente del Instituto Internacional de Literatura Iberoamericana hizo circular la carta que debía enviarse al presidente Santos entre un respetable número de intelectuales de Europa y ambas Américas. A solicitud del presidente del Instituto, dicha carta, fué escrita por el doctor Carlos García-Prada, colombiano él mismo y gran admirador del maestro.

Como el lector podrá comprobar, este documento fué suscrito por más de sesenta figuras de incontrovertible autoridad, procedentes de dieciséis países de ambas riberas del Atlántico, y representantes de las más prestigiadas instituciones de cultura de los tres continentes. Tales el Collége de France, el Institute of International Education, las Universidades de Munich, Burdeos, Harvard, California, Columbia, México, La Habana y unas ocho o diez más, así como otras muchas corporaciones: academias de la lengua, asociaciones de escritores, bibliotecas, etc. Dignamente representados estaban también los órganos de especialización literaria más acreditados: el Bulletin Hispanique, la Revue de Littérature Comparée, Revista Hispánica Moderna, Revista Bimestre Cubana, Revista Nacional de Cultura, Revista de las Indias, Revista Cubana, Repertorio Americano, etc. Nosotros, de Buenos Aires y la Sociedad Argentina de Escritores, que no tuvieron noticia del proyecto a tiempo, se adhirieron a él con entusiasmo unas semanas más tarde. Muchos de los firmantes ostentaban, además, la representación diplomática de sus respectivos países.

Difícilmente podría encontrarse en los anales de la cultura hispana otro caso de petición más autorizada y unánime, tanto por la calidad de los peticionarios y la solvencia de las instituciones representadas, cuanto por la heterogeneidad étnica, creencias e ideologías encarnadas en los respectivos firmantes. Anglosajones e hispanos de ambos mundos, alemanes y franceses, judíos y gentiles, católicos y protestantes, conservadores y comunistas, todos concurrieron gozosos a apoyar con el prestigio de su nombre el acto de cultura y de 
justicia que del gobierno colombiano se demandaba. Lo mismo ha ocurrido en el caso actual. Pocos hombres en América podrían aunar elementos tan disímiles y despertar una simpatía tan admirativa y cordial como la evidenciada en estos dos intentos de honrar a don Baldomero Sanín Cano.

¿Cómo acogió el gobierno colombiano la solicitud? ¿Cuál fué la reacción de los hombres de letras que en aquel instante ocupaban las más altas magistraturas del país ante un hecho tan inusitado y lisonjero para Colombia? Este es un capítulo penoso y desilusionante, no sólo para los que intercedieron en pro del honor que se pedía, sino para cuantos nos preocupamos por los destinos de la cultura americana. Porque debe señalarse aquí el hecho de que con aquel frustrado proyecto - como con el más modesto que ahora cristalizase perseguían dos propósitos: el primero consistía en testimoniar al glorioso anciano la admiración y la gratitud que todos hemos sentido siempre por él y reconocer públicamente la trascendente significación cultural de su labor; el segundo y acaso más provechoso fin era rendir un notable servicio a la cultura americana recogiendo en volúmenes la obra dispersa del maestro para hacerla circular por América como un modelo digno de emulación y un estímulo para las nuevas generaciones.

Las personas responsables de la iniciativa de 1939 ignoran todavía hoy cuál fué la reacción de los gobernantes de Bogotá y las causas verdaderas que impidieron la realización del proyecto. Lo único cierto y fuera de conjeturas es que el gobierno echó la demanda en saco roto y no hizo absolutamente nada. El único testimonio o fe de vida que el gobierno dió consiste en una breve carta o acuse de recibo de los documentos remitidos, enviada por el secretario del presidente Santos al presidente del Instituto Internacional de Literatura Iberoamericana y que éste conserva.

Tan pronto como tuvo noticia del proyecto la juventud intelectual colombiana, se organizó en Bogotá un comité gestor del homenaje que empezó a funcionar con gran entusiasmo. Mas ni la diligencia internacional ni la devoción doméstica lograron conmover a los señores arcontes colombianos. ¿Por qué? Sería en extremo interesante conocer la verdad. Hasta el que esto escribe han llegado rumores que es preferible no tomar en cuenta ni comentar...

Para concluir estas referencias que podríamos llamar históricas vamos a transcribir unas palabras contenidas en el medular testimo- 
nio con que Gabriela Mistral enaltece este homenaje. La poetisa andaba en Europa en 1939 y no tuvo -ni tiene todavía- noticia de lo que en aquel año se solicitó del gobierno colombiano. $\mathrm{Y}$ no obstante, véase como sin saberlo pone de nuevo el dedo en la llaga y llama una vez más a capítulo a los magistrados de Bogotá para que no priven a nuestra América de la cosecha intelectual de mayor alcance que hasta ahora ha producido ningún colombiano. He aquí el ruego de la poetisa:

\begin{abstract}
"En estos días de su jubileo, nosotros esperamos del gobierno colombiano el acto que llaman los hacendados 'prestar al vecino semilla cernida'. Lo que está haciendo Cuba con Martí y lo que hace a estas horas México con don Justo Sierra, tiene que hacerlo la Colombia letrada por su pedagogo social y su ensayista divulgador de culturas. Que algo quede de las fiestas del año 48 $\mathrm{y}$ que eso sea un reparto del sustento recogido, $\mathrm{y}$ hasta hoy quedado, dentro de los silos colombianos. Ni la propia España le conoce lo bastante, $\mathrm{y}$ en el sur son muchos los que le admiran más por citas que por textos íntegros icosa increíble! Así es de grande el desorden de la lectura en nuestros pueblos y así es la falta de jerarquía que gobierna el negocio librero y hasta las clases de literatura hispanoamericana."
\end{abstract}

Como se ve Gabriela reitera la demanda de 1939, la cual se mantiene vigente. Repitamos aquí las palabras finales del modestísimo crítico cubano en 1937: "el gobierno y la intelectualidad colombianos tienen la palabra". Aún están a tiempo de volver por el prestigio de su país y rendir este provechoso servicio a la cultura americana. Acaso en estos instantes en que los hombres de letras no figuran tan prominentemente en las altas esferas burocráticas de Bogotá, el ambiente sea más propicio para empresas de esta índole. Parece una paradoja y un contrasentido. Mas de estas antinomias y absurdos se compone la tela de nuestras vidas y la urdimbre de nuestro ambiente político. ¿No fué Jean Cocteau quien dijo que la única ley que explica la idiosincrasia hispana es la del absurdo?

He aquí ahora, en apoyo del voto de Gabriela Mistral, los documentos enviados en 1939 al doctor Eduardo Santos. Autor de la primera de dichas cartas fué el presidente de la institución que apadrinó el proyecto; la segunda, o sea la firmada por los solicitantes, como ya se dijo, fué escrita por el doctor Carlos García-Prada. 
Los Angeles, Calif., 12 de septiembre de 1939.

Excmo. señor doctor Eduardo Santos, Presidente de Colombia.

\section{Señor :}

Es para mí un motivo de particular satisfacción hacer llegar hasta S. E. la adjunta carta firmada por un respetable número de los más ilustres intelectuales de ambas Américas y de Europa. No fué la intención del Instituto solicitar la adhesión de la mayoría de los escritores de América. Sólo invitó a unas cuantas figuras representativas de la cultura iberoamericana o que por su difusión y conocimiento se interesan en otros países.

Rectores universitarios, catedráticos, académicos, historiadores, novelistas, poetas, críticos, ensayistas, ministros y embajadores, todos beneméritas figuras del intelecto europeo y americano, han respondido con entusiasmo a nuestra invitación para honrar al preclaro maestro de las letras americanas, don Baldomero Sanín Cano. Créame, señor Presidente, que la colección de cartas que obra en nuestro poder en respuesta al llamamiento de este Instituto, constituye ya de por sí un tributo de unánime admiración hacia el gran ensayista y crítico y una evidente demostración de la deuda intelectual que todos en América tenemos contraída con don Baldomero Sanín Cano. Como patriota colombiano, como intelectual y como la más alta representación oficial de ese admirable país, estoy seguro de que S. E. se sentirá orgulloso de saber que esta iniciativa ha sido acogida con jubilosa unanimidad por cuantos hasta ahora la conocen.

No dudo de que S. E. pondrá a contribución todos los recursos que su patriotismo y su alta investidura ponen a su alcance, para que este homenaje continental que proponemos se realice y tenga todo el relieve y toda la significación cultural que los méritos del homenajeado y la gloria intelectual de América merecen. Para todos nosotros es ya suficiente garantía de realización inmediata, la feliz coincidencia de dirigir los destinos de Colombia en estos momentos hombres de la talla intelectual de S. E., los doctores López de Mesa, Lozano y Lozano y tantos otros beneméritos de la cultura colombiana.

Con mi más alta consideración y respeto. 
A1 Excmo. señor doctor Eduardo Santos,

Presidente de Colombia.

\section{Señor presidente:}

Los subscritos, con el mayor respeto y movidos por hondo sentimiento de amor a las glorias de América, nos dirigimos a S. E. para encarecerle que ponga su entusiasmo generoso y los recursos que le da su alta posición oficial, en el empeño que todos perseguimos de rendirle un homenaje a don Baldomero Sanín Cano, maestro de las juventudes americanas.

Todos los pueblos cultos del mundo han experimentado siempre legítimo orgullo y sin par regocijo al honrar en una forma $\mathbf{u}$ otra a sus hijos más ilustres, y al hacerlo, se han aprovechado del momento oportuno. La América vive un momento decisivo de su historia, $y$, en la paz y en el honor, busca con afán la manera de afirmar categóricamente su unidad espiritual y cultural. Por eso la América entera sabe que es preciso rendirle ahora el homenaje debido a uno de sus más preclaros conductores, don Baldomero Sanín Cano, varón ejemplar por sus muchas virtudes, apóstol vigilante de la paz, la verdad y la justicia, maestro insigne si los hay por su sabiduría y por la sencilla autoridad purísima de su mensaje de liberación social, espíritu noble que posee y expresa las más genuinas aspiraciones de los pueblos americanos.

Nosotros creemos, señor Presidente, que el homenaje a Sanín Cano, para que sea digno de él y de América, debe consistir especialmente en la publicación, por cuenta del gobierno de su patria, de las Obras completas de Sanín Cano -que podrá hacerse con grandes ventajas bajo su propia dirección y antes de que abandone el mundo de los vivos- y en la preparación y publicación de dos o más volúmenes que contengan los trabajos que sobre el maestro y su obra o sobre temas afines escriban en su honor sus admiradores y discípulos, que son tantos en el mundo occidental.

La publicación de este homenaje bajo los auspicios del gobierno de su Excelencia, será un acto de gran trascendencia para la cultura iberoamericana y un alto timbre de honor para Colombia.

La feliz iniciativa que el Instituto Internacional de Literatura Iberoamericana ha prohijado, de rendirle en esta forma un homenaje internacional al maestro Sanín Cano, merece nuestro aplauso, y, 
para apoyarla, nosotros estamos dispuestos a hacer todo lo que esté a nuestro alcance y esperamos de S. E. la acogida favorable que merece.

De S. E. atentos y seguros servidores.

Pedro de Alba (Subdirector de la Unión Panamericana); Rafael Angarita Arvelo (venezolano); José G. Antuña (uruguayo); Germán Arciniegas (colombiano); Rafael Arévalo Martínez (Director de la Biblioteca Nacional de Guatemala); A. Arias Larreta (peruano); Mariano Azuela (mexicano); Luis A. Baralt (Universidad de La Habana); Roberto Brenes Mesén (costarricense); Américo Castro (español, Universidad de Wisconsin); George Cirot (Decano honorario de la Facultad de Letras, Universidad de Burdeos; secretario del Bulletin Hispanique) ; José María Chacón y Calvo (cubano, Director de Cultura, Secretaría de Educación; Director de la Revista Cubana); Hernán Díaz de Arrieta Alone (chileno); Enrique Díez-Canedo (español); Fernando Díez de Medina (boliviano); Stephen Duggan (norteamericano, Director del Institute of International Education) ; John E. Englekirk (Universidad de Tulane) ; J. D. M. Ford (Universidad de Harvard) ; Rómulo Gallegos (venezolano) ; Federico Gamboa (Director de la Academia Mexicana de la Lengua); Joaquín García Monge (Director del Repertorio Americano); Carlos García-Prada (colombiano) ; Enrique González Martínez (mexicano) ; Paul Hazard (profesor del College de France; Director de la Revue de Littérature Comparée); Alfonso Hernández Catá (cubano); Juana de Ibarbourou (uruguaya); Julio Jiménez Rueda (Universidad Nacional de México); Willis Knapp Jones (Universidad de Miami) ; Sturgis E. Leavitt (Universidad de Carolina del Norte); Félix Lizaso (cubano); Jorge Mañach (cubano) ; E. K. Mapes (Universidad de Iowa); Juan Marinello (cubano); Percy Alvin Martin (Universidad de Stanford) ; Concha Meléndez (Universidad de Puerto Rico); Octavio Méndez Pereira (Rector de la Universidad de Panamá); Francisco Monterde (Universidad Nacional de México); Tomás Navarro Tomás (español, Universidad de Columbia) ; Federico de Onís (español, Universidad de Columbia, Director del Instituto de las Españas y de la Revista Hispánica Moderna) ; Fernando Ortiz (ex presidente de la Academia de la Historia de Cuba; presidente de la Institución Hispano Cubanâ de Cultura; director de la Revista Bimestre Cubana); Gustavo 
Adolfo Otero (boliviano) ; Antonio S. Pedreira (director del Departamento de Estudios Hispánicos, Universidad de Puerto Rico); Mariano Picón Salas (Director de la Revista Nacional de Cultura, Caracas); Alfonso Reyes (mexicano); Luis Rodríguez Embil (cubano); Manuel Rojas (ex presidente de la Sociedad de Escritores Chilenos); José Rubén Romero (mexicano); Concha Romero James (Director de la Oficina de Cooperación Intelectual de la Unión Panamericana, Washington); Pedro Salinas (español, Wellesley College); Daniel Samper Ortega (colombiano); Luis Alberto Sánchez (Presidente de la Alianza de Intelectuales de Perú); Arturo Scarone (Director de la Biblioteca Nacional, Montevideo); Dorothy Schons (Universidad de Texas) ; Pedro Sotillo (Director de El Universal, Caracas) ; Jefferson R. Spell (Universidad de Texas) ; Franz Tamayo (boliviano); Arturo Torres-Rioseco (chileno, Universidad de California) ; Arturo Uslar Pietri (venezolano); Medardo Vitier (cubano); Karl Vossler (Universidad de Munich); Alberto ZéregaFombona (venezolano); Alberto Zum Felde (uruguayo).

Por la copia,

Manuel Pedro González, University of California, Los Angeles. 
